\title{
Direito e Literatura: repensando a diversidade de gênero através de uma perspectiva literária ${ }^{1}$
}

\author{
Derecho y literatura: repensar la diversidad de género desde una \\ perspectiva literária
Law and literature: Rethinking gender diversity through a literary perspective

\author{
Thaís Maciel de Oliveira²
}

\begin{abstract}
Resumo
Por meio de uma interpretação literária, este estudo tem por escopo problematizar a delimitação de estereótipos no meio social. Dessa forma, contextualizando as imposições morais e comportamentais com os personagens literários do romance Senhora, de José de Alencar, objetiva-se propiciar uma dialética queer de reconhecimento da diversidade de gênero. Portanto, a representação feminina personificada em Aurélia apresenta quebra de estereótipos, quando esta assume, no romance, comportamentos específicos ao gênero masculino. Nesse aspecto, o meio social e cultural também são problematizados como delimitadores do comportamento do indivíduo. O caminho utilizado para produção do presente trabalho foi o método de raciocínio dedutivo, e o método de procedimento escolhido foi o qualitativo. Desse modo, contextualizando as ideologias e posicionamentos sociais do século XIX com a sociedade do século XXI, há possiblidades de construir uma narrativa epistemológica queer voltada para o reconhecimento da diversidade. Logo, o romance Senhora fornece subsídios para uma discussão sobre os papéis normativos do gênero masculino e feminino, assim como os conflitos morais e sociais que giram em torno do indivíduo na sociedade pós-moderna.
\end{abstract}

Palavras-Chave: Dialética; Direito; Gênero; Literatura; Reconhecimento.

\section{Resumen}

A través de una interpretación literaria, este estudio tiene como objetivo discutir la demarcación de los estereotipos en el entorno social. Así, contexto de las restricciones Morales y de comportamiento con los personajes literarios de la novela la señora de José de Alencar, el objetivo es proporcionar un reconocimiento de diversidad de género queer de dialéctica. Por lo tanto, la representación femenina en Aurelia presenta rompiendo estereotipos, cuando asume, en la novela, comportamientos específicos del hombre. En este sentido, el entorno social y la cultura también son problematizados como delimitadores del comportamiento del individuo. La ruta de acceso utilizada para la producción de este trabajo fue el método de razonamiento deductivo y el método elegido fue el procedimiento cualitativo. Así, contextualizar las ideologías y las posiciones sociales del siglo XIX con la sociedad del siglo XXI, hay posibilidades de construir un relato centrado en queer reconocimiento epistemológico de la diversidad. Pronto la novela señora proporciona subsidios para una discusión de las funciones reguladoras de varón y mujer, así como los conflictos morales y sociales que giran en torno al individuo en la sociedad postmoderna.

\footnotetext{
${ }^{1}$ Artigo apresentado no Simpósio Temático ST 02 - Saberes de desaprendizagens, Artes, Gênero e Sexualidade, durante o II Seminário Latino-Americano de Estudos em Cultura - SEMLACult em Foz do Iguaçu/PR, Brasil, 2018

${ }^{2}$ Mestranda bolsista CAPES/TAXA do Programa de Pós-graduação em Direito Stricto Sensu - Mestrado em Direitos Especiais da Universidade Regional do Alto Uruguai e das Missões - Campus Santo Ângelo, Rio Grande do Sul, Brasil..E-mail: adv.thaismaciel@gmail.com.
} 
Palabras clave: Dialéctica; Ley; Género; Literatura; Reconocimiento.

\begin{abstract}
Through a literary interpretation, this study aims to discuss the demarcation of stereotypes in the social environment. Thus, moral and behavioural constraints context with the literary characters of the novel Lady of José de Alencar, the goal is to provide a dialectic queer gender diversity recognition. Therefore, the female representation embodied in Aurelia presents breaking stereotypes, when this assumes, in the novel, male-specific behaviors. In this respect, the social environment and culture are also problematizados as delimiters of the behavior of the individual. The path used for the production of this work was the method of deductive reasoning, and the method chosen was the qualitative procedure. Thus, contextualizing the ideologies and social positions of the 19th century with 21ST century society, there are possibilities to build a narrative focused on queer epistemological recognition of diversity. Soon the novel Lady provides subsidies for a discussion of the regulatory roles of the male and female, as well as the moral and social conflicts that revolve around the individual in postmodern society.
\end{abstract}

Keywords: Dialectic; Law; Genus; Literature; Recognition.

\title{
1. Introdução
}

A partir de uma perspectiva literária, o presente artigo busca aproximar o Direito da Literatura com o intuito de instigar uma aproximação do leitor com temas sobre diversidade de gênero, relação entre integração da sociedade e anulação da individualidade. Desse modo, a partir do acostamento entre Direito e Literatura se buscou avizinhar o abstrato do concreto, com vistas à humanização do Direito.

A reflexão fornecida pela obra Senhora, através do método de raciocínio dedutivo auxilia a compreensão da sociedade a luz dos conceitos como as relações de poder, dicotomia de gênero e a construção política do sujeito. Igualmente, a pesquisa pela abordagem qualitativa auxilia a compreensão e aproximação do mundo fictício e do real.

Com efeito, os personagens da obra Senhora, Aurélia e Fernando Seixas, são estudados em razão de suas peculiaridades e contradições. A construção identitária do sujeito também entra no objetivo do presente estudo, diante do enfoque cultural e social que o trabalho propõe. Como resultado das delimitações sociais, o indivíduo é problematizado diante da anulação de sua individualidade em prol do interesse coletivo.

Nesse aspecto, as delimitações dos papéis sociais entram em pauta frente aos conceitos de masculinidade e feminilidade presentes na narrativa. Portanto, a narrativa ficcional tem uma importante contribuição para o século XXI, principalmente frente a matriz colonial reminiscente e diante das questões de discriminações e exclusões que a contemporaneidade ainda enfrenta.

Consequentemente, a sociedade da aparência ainda anula individualidades em pleno século XXI, portanto a discussão sobre a diversidade de gênero, os papais sociais e a cultura 
patriarcal, constituem conceitos fundamentais para instigar uma dialética do reconhecimento e do respeito com o outro.

\section{Viés relacional entre direito e literatura}

A busca pela humanização do direito constitui uma importante perspectiva hermenêutica do século XXI. A produção de saberes necessita da superação das expectativas coloniais, pois a reprodução de verdades cristalizadas, enraizadas em preconceitos não comporta a extensa sociedade multicultural da contemporaneidade. Logo, um dos desafios da atualidade concentra-se em fomentar um pensar diverso dos estereótipos culturais.

A aproximação do direito com a literatura, nesse sentido, possibilita a contextualização de questões centrais como: gênero, diversidade identitária e reforma do pensamento social, de uma maneira mais empática ao leitor. Portanto, essa forma de olhar o direito a partir de uma concepção humanista e pluralista, difere do olhar do senso comum da racionalidade pública.

Com efeito, a imaginação literária que os discursos narrativos produzem, permitem a compreensão de um contexto social diferente da realidade à que estão inseridos. Atribuindo a emoção um papel imprescindível para interpretação do diferente.

A literatura como visão humanista do direito é compreendida "como uma nova forma de redescoberta da própria sensibilidade e da sensibilidade como forma de compreensão além do pensamento" (WARAT, 2010, P. 119). Logo, a literatura representa uma ponte essencial para a concretização da justiça social.

Destarte, a função da sensibilidade da literatura "além de proporcionar ao ser humano uma existência mais poética [...] a literatura instaura experiências em quem lê, de modo a exercer diferentes tipos de impactos, porque é problematizada em diferentes níveis e de diferentes situações" (DUARTE, MADERS, 2017, p. 514-516).

O direito, nesse aspecto, se aproxima da imaginação literária diante das reivindicações do saber contemporâneo. Além disso:

Pelas infinitas possibilidades de interpretação, pela não fragmentação do homem, pela valorização da emoção, pela abertura ao pensar diferente, a literatura nos mostra a urgência de reintegrarmos o homem. A vivência da leitura de um conto ou um poema não é analisada em partes, primeiro racionalmente e podeis emocionalmente. Mente, alma, corpo e coração são implicados ao mesmo tempo, conjuntamente e é daí que se extrai sua beleza, que se experimenta o prazer. (MOREIRA, OLIVEIRA, 2015, p.16). 
A obra literária serve como subsídio para reflexão moral e social, permitindo o diálogo sobre diversas questões problemáticas da vida contemporânea. Nesse sentido, a imaginação literária interliga o leitor ao personagem, aflorando sentimentos ao leitor e o conectando intimamente com a literatura, promovendo a identificação e simpatia, do leitor com os personagens da obra.

\subsection{A personagem Aurélia e o padrão hegemônico}

Nessa tangente, a obra literária Senhora, de José de Alencar, possibilita a compreensão de ideologias e posicionamentos do século XIX, igualmente como os costumes e práticas sociais normatizados na época. Aurélia, personagem central desse Romance, personifica uma inversão de papéis, ao assumir atitudes masculinizadas na trama. Entretanto, ao longo na obra a personagem sofre diante das convenções sociais.

Durante seu crescimento, a personagem é edificada com base na ideologia de que o matrimônio representa felicidade. Dessa forma, ao adquirir riqueza, em uma inversão das relações de poder, "compra" seu marido, em uma ambiguidade de atitudes sinalizando a busca pela felicidade diante das pressões sociais.

Aurélia em várias partes da obra salienta a necessidade de reconhecimento social:

Daí encaminhou-se ao piano, que é para as senhoras como o charuto para os homens, um amigo de todas as horas, um companheiro dócil, e um confidente sempre atento. Ao abrir o instrumento, lembrou-se de que não era próprio a uma noiva de véspera entregar-se a esse passatempo, quando vizinhos e criados, todos deviam supô-la àquela hora engolfada na felicidade de amar e ser amada. Ah! Ela não conhecia essa aurora mística do amor conjugal, que se lhe transformara em vigília de angústia e desespero. Mas adivinhava qual devia ser a transfusão mútua de duas almas, e compreendia que, ávidas uma da outra, não se podiam alhear em estranho passatempo (ELENCAR, 1997, p. 53)

O confronto existente em várias partes da obra; do indivíduo com a sociedade, simboliza os aspectos da pressão social que a sociedade apregoa na delimitação de estereótipos. O reconhecimento do outro, nesse sentido, é feito a partir do lugar social que ocupa, ou seja, a sociedade delimita e constrói fronteiras entre aqueles que simbolizam o padrão cultural, a norma. Nesse termos, os outros são denominados a partir desse referencial de normal.

O desenvolvimento da identidade pessoal de um sujeito está ligado fundamentalmente à pressuposição de determinadas formas de reconhecimento por outros sujeitos; pois, com 
efeito, a superioridade da relação interpessoal sobre a ação instrumental consistiria manifestamente em que ela abre reciprocamente para os sujeitos comunicantes a possibilidade de se experienciar em seu parceiro de comunicação como o gênero de pessoa que eles reconhecem nele a partir de si mesmos (HONNET, 2009, p. 78).

Destarte, o reconhecimento é um importe fator na edificação do indivíduo. Charles Taylor no seu livro Multiculturalismo (1994), também pontua sobre a importancia do correto reconhecimento para o indivíduo. Já que seu incorreto reconhecimento por parte da sociedade pode ocasionar uma auto depreciação.

De fato, constitui realidade indubitável, tanto na obra quanto na atualidade, que as práticas sociais reiteram discursos de gênero extremamente fundamentalistas, que segregam direitos em prol de uma verdade particular. Essa verdade particular da cultura dominante é perpassada como universal para sociedade. É pontuada como anterior a cultura, como princípio basilar.

Em suma:

Definir alguém como homem ou mulher, como sujeito de Gênero e de sexualidade significa, pois, necessariamente, nomeá-lo segundo as marcas distintivas de uma cultura - com todas as consequências que esse gesto acarreta: a atribuição de direitos ou deveres, privilégios ou desvantagens. Nomeados e classificados no interior de uma cultura, os corpos se fazem históricos e situados (LOURO, 2013, p. 95).

Percebe-se que, as convenções, representações e símbolos culturais interferem na construção da identidade do indivíduo. Dessa forma, a norma heterossexual representa requisito para pertencer a um grupo social. Nesse aspecto, o vínculo social que proporciona formas de reconhecimento é responsável pela organização social vigente.

Com efeito, por mais que em várias passagens da obra Aurélia demonstre uma ruptura dos papéis sociais, a personagem sinaliza angústias diante das práticas sociais, consequentemente, o estereótipo de submissão está incluso em sua subjetividade. Ou seja, mesmo representando papéis diversos da perspectiva da época, Aurélia está incluída naquela sociedade. Logo, conforme as convenções sociais pressionam, a personagem cumpre sua função social.

\subsection{Fernando seixas e as visões de masculinidade}


O personagem Fernando Seixas é representado como um homem ambíguo, demonstrando facetas positivas e negativas da moral. A simbologia em torno do personagem personifica o confronto do indivíduo com seus desejos e padrões impostos pela sociedade.

A oposição dos estereótipos presente na obra, principalmente na figura do personagem Fernando é representada por sua busca em concretizar suas ambições e sua inclusão na delimitação da sociedade como normalidade do gênero masculino. A relação de poder presente entre os personagens Aurélia e Fernando muitas vezes apresenta contradições. Em muitas passagens da obra, Aurélia simboliza o domínio das relações de poder com base em seu enriquecimento.

A masculinidade do personagem ao incorporar as práticas sociais exigidas pela sociedade transpassa por mudanças de comportamento. A dialética transmitida pela obra, evidencia uma crítica a práxis social da vida conjugal. Nessa concepção, a diversidade identitária sob o enfoque cultural é relegada em prol do interesse coletivo.

O indivíduo é produto da relação especial reflexiva entre o eu e os outros. Logo, o indivíduo é produto dessa relação reflexiva, dos conceitos e conjuntos de valores que ele absorve.

\footnotetext{
Nenhuma experiência é mais central que essa relação ao outro pela qual um e outro se constituem como sujeitos. Mas seria artificial opor essa relação privada à vida pública. Todos os indivíduos estão presos numa rede de papéis, existem para outrem e o encontro do outro jamais se opera em terreno aberto, como numa cena de filme onde dois personagens surgissem, um diante do outro, em um cenário vazio. É necessário sobretudo que o reconhecimento do outro como sujeito leve a participar dos esforços do outro para se libertar das exigências que o impedem de viver como sujeito (TOURRAINE, 1994, p. 292).
}

Essa homogeneização através do poder visa padronizar o indivíduo facilitando o poder da maioria sobre o sujeito individualizado. Essa unificação das características individuais em prol de uma maioria é embasada em fundamentalismos que apregoam a edificação de estereótipos. A sociedade, nesse aspecto, delimita o comportamento dos seus cidadãos, e os enquadra em posições de hierarquia conforme interesse da cultura local.

Nesse enfoque, percebe-se ao decorrer da obra, os anseios da sociedade em naturalizar os papeis de gênero, considerando-a como algo biológico do ser humano, anterior a cultura. Esse argumento moralista que apregoa a dicotomia de gênero como verdade universal, participa ativamente da construção indenitário do indivíduo (BUTLER, 2017). Quem não aceita essas ideologias estereotipadas não é integrado no grupo social, passando a ser sujeito à margem da sociedade ou socialmente discriminado. 
Principalmente na obra referenciada, percebe-se em vários aspectos a necessidade do enquadramento social por parte do indivíduo. Tanto os personagens Aurélia e Fernando Seixas anulam sua individualidade em face dos papeis sociais.

A coisificação de Seixas é visualizado na obra quando Aurélia adquire o personagem. Nesse aspecto, Seixas constituí o objeto de desejo da personagem Aurélia. Consequentemente, a personagem feminina de acordo com a cultura patriarcal, apenas alcança sua plenitude a partir do casamento. Logo, a plenitude referenciada na obra representa a necessidade dos sujeitos em construir sua identidade social.

Com efeito, os princípios morais enaltecidos na obra têm uma inter-relação com os anseios da sociedade. Ou seja, os valores morais aceitos pela sociedade estão relacionados com a fonte de poder dominante local. Essa regulamentação dos valores morais normatizados pelo coletivo apresenta raízes históricas que variam culturalmente de acordo com a política de cada época. Neste aspecto, a construção das identidades dos indivíduos leva a análise tanto dos sistemas socioculturais que modelam a moral, quanto a interpretação do considerado normal em cada momento histórico. Portanto, o modo pelo qual os papeis de gênero são estruturalizados revelam as formas de poder que sujeitam os indivíduos em determinada época (CONNEL, PEARSE, 2015).

\subsection{Ambiguidades presentes na obra}

A obra literária Senhora apresenta uma narrativa patriarcal e patrimonialista, assinalando que o empoderamento feminino apenas se verifica na aquisição de patrimônio. Destarte, a personagem Aurélia ao adquirir uma postura de submissão ao final da narrativa volta aos ideais apregoados pela sociedade da época.

Com efeito, a reflexão da obra subjaz o pensamento colonial que a mulher apenas alcança sua completude quando retorna ao domínio dos homens. Entretanto, mesmo diante dessa contradição, a obra Senhora:

Ajuda a compreender algumas representações construídas sobre homens e mulheres numa perspectiva pedagógica que instruiu o leitor, por meio de modelos exemplares, a compreender o mundo e a si, a pensar, a sentir e a se comportar. Apresenta um conhecimento sobre as relações entre os gêneros, ao abordar as regras sociais da época em relação às experiências amorosas e às práticas moralmente aceitas, auxiliando na formação de novos cidadãos. Suas figuras idealizadas veiculam mensagens na intenção de forjar uma realidade para além da ficção, orientando e ajudando as pessoas a compreender como deveriam se relacionar ou como se esperava que elas se relacionassem na nova conjuntura social (BORGES, 2012, p. 312). 
Dessa forma, a ambiguidade presente na obra da racionalidade em contraposição a emoção tem um caráter pedagógico para auxiliar a construção dos papeis de gênero. Neste dispersão, questionar o real e o factual no interior de uma cultura fundamentalista põe em questão a estrutura que articula essas identidades.

A diversidade identitária que a obra Senhora possibilita a reflexão, refere-se na compreensão da complexidade que consubstancia a identidade do indivíduo. Portanto, a busca pelo indivíduo de se integrar na sociedade resulta na anulação de sua individualidade. Nesse sentido, realizando uma interligação com a sociedade atual, os indivíduos precisam do reconhecimento coletivo para se sentirem incluídos na sociedade (HONNET, 2009).

A construção de sua identidade é interferida pelo meio social em que está inserido. Portanto, uma narrativa queer ${ }^{3}$ voltado para não delimitação de estereótipos possibilita a edificação do indivíduo não delimitado por uma dicotomia dos papeis sociais (BUTLER, 2017).

Os estereótipos sociais, nesse sentido, reduzem o indivíduo em uma qualificação reducionista de sua subjetividade. Entretanto, a complexidade do ser não comporta uma simplista qualificação estereotipada. A diversidade de gênero presente hoje na sociedade requer um mútuo reconhecimento da complexidade, do que significa ser um sujeito de direitos humanos. Principalmente em um ambiente democrático, é necessário possibilitar não só os deveres do sujeito, mas também seus direitos.

A reflexão que a obra propõe de uma perspectiva voltada às diferenças é primordial diante do panorama brasileiro atual. A questão da diversidade de gênero representa uma questão central da contemporaneidade. Desse modo, a diversidade identitária e o reconhecimento constituem a quintessência da constituição de uma sociedade multicultural. Principalmente em um Estado Democrático de Direito, a diferença precisa ser cingida a um patamar de respeito e corretamente reconhecida para poder proporcionar uma eficaz política de direitos humanos garantidos pela Constituição da República Federativa do Brasil.

\subsection{Contribuições para o século XXI}

\footnotetext{
${ }^{3}$ A palavra Queer é proveniente da língua ingressa e significa diferente, excêntrico. A palavra foi utilizada pela feminista Judith Butler como forma de designar quem não deseja ser delimitado pela dicotomia de gênero.
} 
A relação da literatura com do direito possibilita uma visão mais humanista do contexto social em que se referência. Assim, a aproximação do abstrato e do concreto contribuem para edificação de leitores sensíveis aos questionamentos e costumes da época. Possibilitando uma importante reflexão com as questões de gênero e a superação das perspectivas coloniais.

A obra citada apresenta uma importante reflexão sobre a sociedade da aparência. Os personagens Aurélia e Fernando Seixas anulam sua individualidade em busca de suprir os anseios da sociedade em que estavam inclusos. Esta caracteristica de perder sua individualidade em prol do interesse coletivo ainda perpassa o imaginário da sociedade do século XXI.

A miscigenação de identidades e pluralidades de culturas consubstanciam a sociedade multicultural contemporanea. Nesse aspecto, as identidades se caracterizam por representar uma totalidade de um conjunto, uma diferença comum. Assim, brilhantemente Eligio Resta clarifica sobre identidade:

O espaço da identidade está sempre em percurso que vai de uma coisa a outra, que necessita do outro para se realizar como identidade: assim, posso dizer sobre o ser "eu" ao mesmo tempo em que continuo a ser italiano, mas posso afirmar também que sou eu porque não sou austríaco ou Imperador da China (RESTA, 2014, p. 24).

Nesse aspecto, as múltiplas identidades posicionam a forma de ver o mundo a partir da diferença. Portanto, a contemporaneidade comporta o desafio de conviver com o diferente em uma mesma comunidade. Nesse sentido, o sistema patriarcal presente na obra ainda constituí ideologia padrão da sociedade contemporanea. Ou seja, a construção política do sujeito ainda é embasada pela dicotomia epistemológica.

Desse modo, a construção identitária do indivíduo é tento uma questão individual como política, diante das relações de poder. Portanto, o padrão normativo perpassado representa as relações dominantes que regularizam os processos de interação. Segundo Butler:

Uma das maneiras pelas quais o poder é ocultado e perpetuado é pelo estabelecimento de uma relação externa ou arbitrária entre o poder, concebido como representação ou dominação, e o sexo, concebido como energia vigorosa mas toldada, à espera de libertação ou auto expressão autêntica (BUTLER, 2017, p. 166-167).

Percebe-se diante do intento que os papeis sociais do indivíduo são produções fictícias das relações de poder. Esta fantasia do que é considerado normal e o que é diferente são instituídos e inscritos sobre a superfície dos corpos (LOURO, 2013). Com efeito, a noção de identidade certa e errada é revestida pelas práticas culturais e discursivas de cada época. 
Como resultado desse processo cultural, o indivíduo que não se enquadra no padrão segue em conflitos sociais frente à busca por reconhecimento como sujeitos de direitos em um Estado Democrático de Direito. O Estigma social sob pretensões mitigadas representa a lógica dicotômica que conceptualiza as relações de poder.

Nesse sentido, caudatário de processos históricos e culturas de segregação, a heteronormatividade sexual qualifica-se como uma herança epistemológica de discursos fundamentalistas de poder. A compreensão dos processos de edificações de verdades absolutas e intransigíveis deflagram os discursos e repetições pelos quais as regras são criadas e reiteradas.

\section{Conclusão}

A diversidade de gênero e os papeis sociais constituem dois temas presentes e recorrentes no Brasil atual. Diante da sociedade pluralista que permeia a sociedade do século XXI, questões sociais se tornam cada vez mais evidentes e críticas. Ou seja, na medida em que essas pluralidades se multiplicam novos direitos são reivindicados.

Seguindo esse contexto, as relações de poder possuem extrema influência na edificação dos estereótipos dominantes. Essa hierarquia social, que enquadra os sujeitos na sociedade, estabelece a dicotomia de gênero como padrão a seguir. O diferente, nesse aspecto é discriminado e segregado.

Logo, redimir o preconceito significa desconstruir o padrão heteronormativo na sociedade. Ou seja, a partir da construção de sujeitos sociais críticos, é possível analisar as influências que edificam as relações entre os sujeitos. Por consequência, compreendendo que os papeis sociais são delimitados por uma cultura dominante, é possível combater esse sistema histórico de dominação e subjugação.

A análise literária, nesse sentido, possibilita a discussão acerca da temática dos papeis sociais, da diversidade de gênero e das relações de poder. Dessa forma, a partir da narrativa em torno dos personagens Aurélia e Fernando Seixas é possivel questionar o papel das relações de poder na edificação dos estereótipos dominantes, assim como analisar o processo cultural que envolve o reconhecimento das identidades.

A epistemologia do padrão normativo revela os processos definidores de identidades. Logo, conclui-se que o reconhecimento da identidade do indivíduo é resultado de uma relação de poder de determinada época. O coletivo, nesse sentido, adapta o indivíduo a sua 
semelhança, para poder apreender a viver em sociedade. Ou seja, sua individualidade é anulada em prol do interesse coletivo.

Doravante a desconstrução de identidades consideradas normais, sua percepção como processo ideológico das relações de poder constitui base para uma cultura de direitos humanos. A narrativa ficcional demonstra a busca dos personagens em suprir os anseios da sociedade da época e como a sociedade acaba anulando suas individualidades.

A sociedade da aparência, nesse aspecto, é produto da matriz colonial que reitera discriminações. Consequentemente, esse conceito de identidade apresenta reminiscência da cultura patriarcal, que embasa o padrão hegemônico como verdade universal.

Dessa forma, diante da multiculturalidade e miscigenação de culturas que constituem as identidades atuais, uma narrativa epistemológica queer voltada para o reconhecimento com as diversidades são bases necessárias para uma sociedade democrática. A diversidade de gênero e as diferenças identitárias fazem parte do pensamento social, portanto questionar as relações de poder dominantes fundamentam esse olhar humanista que o artigo se propõe.

\section{REFERÊNCIAS}

ALENCAR, José de. Senhora. Rio de Janeiro: Ediouro, 1997.

BORGES, Valdeci Rezende. Gênero e mercado matrinomial em Senhora de José de Alencar. Projeto História: Revista do Programa de Estudos Pós-Graduados de História, v. 45, 2012. Disponível em: < https://revistas.pucsp.br/index.php/revph/article/view/15016> Acesso em: 15 ago. 2018.

BUTLER, Judith. Problemas de Gênero: feminismo e subversão da identidade. Tradução Renato Aguiar. - 13 ${ }^{\mathrm{a}}$ ed. - Rio de Janeiro: Civilização Brasileira, 2017.

CONNELL, Raewyn; PEARSE, Rebecca. Gênero: uma perspectiva global. São Paulo: nVersos, 2015.

DUARTE, Isabel Cristina Brettas; MADERS, Angelita Maria. O direito pelos olhares de Palomar. Anamorphosis: Revista Internacional de Direito e Literatura, v. 3, n. 2, p. 489-518, 2017. Disponível em: <https://dialnet.unirioja.es/servlet/articulo?codigo=6255932> Acesso em: 20 jul. 2018.

HONNETH, Axel. Luta por reconhecimento: a gramática moral dos conflitos sociais. Tradução de Luiz Repa; apresentação de Marcos Nobre. - $2^{\circ}$ ed. - São Paulo: Editora 34, 2009.

LOURO, Guacira Lopes. Um corpo estranho - ensaios sobre sexualidade e teoria queer. 2 ed. - Belo Horizonte: Autêntica Editora, 2013. 
MOREIRA, Nelson Camatta; OLIVEIRA, Juliana Ferrari de. Direito e literatura: e os múltiplos horizontes de compreensão pela Arte. Ijuí: Ed. UNIJUÍ, 2015.

Multiculturalismo: examinando a política de reconhecimento. Lisboa: Instituto Piaget, 1994.

SEGATO, Rita Laura. Gênero e colonialidade: em busca de chaves de leitura e de um vocabulário estratégico descolonial. E-cadernos ces, n. 18, 2012. Disponível em: <https://journals.openedition.org/eces/1533 >. Acesso em: 12 jul. 2018.

WARAT, Luis Alberto. A rua grita Dionísio. Direitos humanos da alteridade, surrealismo e cartografia. Rio de Janeiro: Lumen Juris, 2010. 